\title{
«SOY MUSULMANA A MI MANERA» RELIGIOSIDAD, ESPIRITUALIDAD Y LAICISMO DE LAS JOVENES ESTUDIANTES MUSULMANAS
}

\author{
«I AM A MUSLIM IN MY OWN WAY» \\ RELIGIOUSNESS, SPIRITUALITY AND SECULARISM \\ IN YOUNG MUSLIM FEMALE STUDENTS
}

\author{
María JiMÉNEZ-DELGADO \\ Universidad de Alicante
}

Recibido: 31/7/2016

Aceptado: 27/09/2016

Para citar este artículo / To cite this article:

Jiménez Delgado, María. «"Soy musulmana a mi manera". Religiosidad, espiritualidad y laicismo de las jóvenes estudiantes musulmanas». En Nieves Montesinos Sánchez y Beatriz Souto Galván (coords.), Laicidad y creencias. Feminismo/s, 28 (diciembre 2016): 147-168, DOI: 10.14198/fem.2016.28.06

Para enlazar con este artículo / To link to this article:

http://dx.doi.org/10.14198/fem.2016.28.06

\section{Resumen}

Cuando el islam forma parte de las preocupaciones actuales en Europa, esta investigación se pregunta por el significado que tiene ser musulmanas para las hijas de la inmigración marroquí en España, abordando la cuestión religiosa desde la perspectiva y la mirada de las jóvenes estudiantes. Se propone ante todo escucharlas a partir de entrevistas en profundidad. En el centro del debate sobre su religiosidad se sitúa la cuestión de la construcción identitaria, de la igualdad de género, de la libertad individual y de la libertad religiosa.

Las jóvenes estudiantes entrevistadas hacen una resignificación crítica y personal del islam que se resume en esta expresión repetida por muchas de ellas: «soy musulmana 
a mi manera». Esta percepción de su propia religiosidad está condicionada por el género y conecta con una visión transnacional del hecho religioso que deja de vivirse como un fenómeno preferentemente cultural e identitario. Se convierte así en una vivencia íntima y espiritual, en consonancia con la noción de Dios personal de la postmodernidad, definido por Ulrich Beck como la individualización de la religión.

Palabras clave: mujeres, musulmanas, religiosidad, jóvenes estudiantes, generación puente.

\begin{abstract}
At a time when Islam is of current concern in Europe, this research questions the significance of being Muslim for the daughters of Moroccan immigration in Spain, addressing the religious issue from the perspective and standpoint of young student women. It is proposed primarily to hear from them by means of in-depth interviews. The focus of the debate on the religiousness of the young women is the question of identity-construction, gender equality, individual and religious freedom.

Young students interviewed perform a critical and personal redefinition of Islam, which is summed up in the phrase, repeated by many of them: "I am a Muslim in my own way». This perception of their own religion is conditioned by gender, and connects with a transnational view of religion, which is no longer experienced as a preferably cultural and identity phenomenon, in order to become an intimate and spiritual experience, consistent with the notion of a personal God of postmodernism, defined by Beck as the individualization of religion.
\end{abstract}

Keywords: gender, Muslim women, religiousness, young students, bridging-generation. 
¿Cómo me sentiría si fuera [ella]? (Oz 89)

La necesidad de escuchar a las jóvenes, de ponerse en su piel...

\section{INTRODUCCIÓN}

Desde hace más de una década, la cuestión religiosa forma parte de las preocupaciones sociales con dos procesos simultáneos: la progresiva secularización de las sociedades europeas -un proceso consustancial a la modernidad al que ya se refirió Comte, uno de los fundadores de la ciencia sociológica (SánchezCapdequí 170), y que ha sido estudiado con profusión en las ciencias sociales desde Weber y Durkheim-, y un retorno de lo religioso, como protesta contra la modernidad o como una forma distinta de entrar en la misma (Roy 2010, 18). A ello ha contribuido, en las actuales sociedades multiculturales, la población de origen inmigrado y particularmente la procedente de países musulmanes.

En el caso de España, los musulmanes suponen el 3,5 por ciento de la población, es decir, 1,5 millones. Aproximadamente una quinta parte son ciudadanos españoles (Moreras 2015,103), cifra que va en aumento con una proporción significativa de jóvenes, hijos e hijas de la inmigración, que se declaran musulmanes y religiosos.

Existen estudios sobre la religiosidad de los jóvenes, sin embargo no es frecuente abordar la categoría de lo religioso desde la mirada y la perspectiva de quienes son creyentes; esta mirada suele obviarse reduciéndola a menudo a datos estadísticos sobre las creencias, el comportamiento o las actitudes de los jóvenes creyentes.

Este trabajo aborda la cuestión religiosa desde la perspectiva y la mirada de las jóvenes que se declaran mayoritariamente musulmanas. Se propone ante todo escucharlas, entendiendo que es necesario y urgente iniciar un diálogo que parte del derecho de cada persona a expresarse y a juzgar por sí misma sus verdades y creencias religiosas (Gamper 38). Porque como recomienda Martha Nussbaum, es fundamental desarrollar la mirada empática -la representación mental imaginativa positiva- para abordar el análisis de la religiosidad de las jóvenes musulmanas hijas de la inmigración y superar los miedos europeos en relación al islam (Fregosi 9). 
Esta escucha de las jóvenes, pretende ayudar a desactivar prejuicios y a superar una mirada social sesgada sobre las mujeres musulmanas. En el centro del debate sobre su religiosidad se sitúa la cuestión de la identidad, de la igualdad, de la libertad individual y de la libertad religiosa en nuestras sociedades.

Son, por tanto, objetivos de esta investigación: conocer qué concepción tienen las estudiantes musulmanas entrevistadas sobre el islam, cómo perciben y definen su religiosidad, qué cambios se han producido respecto a la generación de sus madres, cómo es la relación con la comunidad musulmana y las mezquitas, cuál es su experiencia sobre el pluralismo religioso y la laicidad en la sociedad española y de qué forma todos estos factores condicionan su construcción personal como sujetos y su participación social como ciudadanas.

\section{NOTAS METODOLÓGICAS}

La opción metodológica elegida para el desarrollo del trabajo de campo y el análisis de los datos, teniendo en cuenta que es una investigación cualitativa, ha sido la Teoría Fundamentada o Grounded Theory (Glaser y Strauss), y el principal instrumento metodológico, la entrevista en profundidad. Esta fue diseñada a partir de un guión flexible que recoge las cuestiones clave en relación a los objetivos del estudio y que ha estado abierto al discurso de las informantes, según los criterios de la Grounded Theory (GT), distinguiendo los momentos iniciales de toma de contacto con fases posteriores de la entrevista donde se asume más control con el fin de satisfacer los criterios de especificidad, amplitud y profundidad (Valles).

Se procedió a la elección de un primer grupo de mujeres jóvenes como muestreo teórico para después ampliarlo progresivamente hasta la saturación del discurso y sobre la base de las necesidades que surgen de la teoría emergente. La relación construida entre la investigadora y las informantes ha sido determinante para conseguir un grado de profundización en los temas que permitiera abordar cuestiones que en un primer momento parecían demasiado intimas y personales para ser explicitadas. Las jóvenes entrevistadas mostraron su deseo de hablar sobre ellas mismas y sobre su religiosidad, temas sobre los que no tienen muchas oportunidades de elaborar un discurso y establecer un diálogo con otros. El primer contacto ha tenido lugar principalmente en los centros donde estudian -en cuatro institutos de educación secundaria (I.E.S.) de la zona norte de la ciudad de Alicante, donde hay una proporción mayor de estudiantes de origen marroquí, y en la Universidad de Alicante-. Se ha entrado en contacto con otras informantes a partir del método conocido como bola de nieve-snowball- (Goodman). Se realizaron veinte entrevistas a estudiantes de 
origen marroquí, diez de ellas a alumnas de educación secundaria y bachillerato y otras diez a universitarias.

\section{EL ISLAM Y LAS JÓVENES EUROPEAS MUSULMANAS}

El islam y la juventud musulmana forman parte de la realidad de Europa y deben ser, por tanto, considerados protagonistas sociales internos, y parte del nosotros (Allievi, Benhabib, 2005), teniendo en cuenta que tiene unas características propias y singulares: es minoritario en un contexto pluralista y laico, constituyendo una minoría en gran medida estigmatizada y no siempre bien integrada, con las consecuencias sociológicas que ello conlleva. Comparativamente, el ciudadano europeo musulmán es más rico, más culto, más libre y con más derechos individuales que el musulmán medio en los países de origen. Hay que tener en cuenta que el islam es internamente plural: en Europa, en concreto, hay cofradías místicas con más diversidad que en otros lugares, reflejada en distintos grupos étnicos, distintas confesiones (suníes, chíies, ismailíes, alevíes, etc.) y distintas lenguas.

Así hay formas distintas de entender el islam en Europa que pueden agruparse de forma simplificada, según Allievi, en estos tres grandes grupos:

- Musulmanes laicos. Son el resultado de un proceso de integración por el cual, sin renunciar a ser musulmanes, pretenden la adaptación y transformación de lo religioso de acuerdo a las mismas pautas que otras religiones. Serían los musulmanes laicizados. Esta tendencia se aproxima al «feminismo laico», que se compromete con los valores ilustrados de la modernidad. Para Nussbaum sería por lo menos cuestionable considerar que son los musulmanes mejor integrados por estar laicizados.

- Musulmanes tradicionalistas. Son los que se identifican con las creencias y prácticas tradicionales de sus países de origen. Utilizan mayoritariamente su lengua materna, tienden a vivir en comunidades más o menos cerradas y siguen manteniendo, en lo posible, las costumbres y rituales de procedencia. Estos musulmanes tradicionales son los más visibles y los más incomprendidos por la sociedad. A pesar de que la comunicación transnacional les permite estar conectados a las sociedades de procedencia a través de la televisión vía satélite y de internet fundamentalmente, y así preservar la tradición y las costumbres, los cambios sociales y culturales también son inevitables. Son musulmanes porque siguen sintiéndose marroquíes o argelinos. 
- Nuevos musulmanes europeos. La tercera forma de ser musulmán es la representada por aquellos que se interesan por la renovación del islam dentro de Europa. Suelen utilizar la lengua del país en el que viven, que en el caso de los jóvenes es la que suelen conocer mejor. Son los que tienen intereses e inquietudes más próximos a los conversos. Ello no quiere decir que sean necesariamente más progresistas y democráticos. Sería el grupo en el que se encontrarían intelectuales europeos como Tarig Ramadan (Allievi 26). Son musulmanes porque no son ya marroquíes, argelinos o turcos. Es en este grupo en el que podemos situar al «feminismo islámico», que tiene su fundamento en la teoría poscolonial, culturalista y anti-universalista y que es crítico con el «feminismo laico». Considera que la liberación de la mujer -musulmana- no está en el abandono de su propia cultura -entendida como cultura religiosa, es decir, cultura musulmana- y en la apropiación de valores externos sino en la interpretación del islam tradicional (Paradela) con un mayor protagonismo de las mujeres en la religión. Es en este contexto que se justifica la reaparición del velo femenino o hiyab. Son quienes consideran que el islam forma parte decisiva de su identidad individual y colectiva.

Es un dato incuestionable que el porcentaje de musulmanes crece rápidamente entre la población religiosa de Europa y que el proceso de secularización afecta principalmente al cristianismo: se construyen más mezquitas y se cierran o se vacían las iglesias. El alejamiento de las jóvenes y los jóvenes de la religión, al menos en Europa, es cada vez mayor. Así lo reflejan todos los estudios sociológicos. En España está realidad se evidencia, desde hace años, en las encuestas del Centro de Investigaciones Sociológicas (CIS), en las realizadas por el Instituto de la Juventud y en los macro sondeos periódicos de la católica Fundación Santa María.

Se puede afirmar que se ha producido un radical debilitamiento de la dimensión religiosa en la juventud española y europea. Año tras año desciende de manera muy significativa el número de jóvenes que afirman creer en Dios. La Encuesta Europea de Valores (EVS), según el informe titulado Jóvenes españoles 2010, publicado por la Fundación Santa María (Valls), ofrece la siguiente evolución del descenso de la fe en Dios durante los últimos veinticinco años: en 1981 creían en Dios el 78\% de los jóvenes; en 1984, la creencia descendió al 71\%; en 1989, se mantuvo en el mismo porcentaje; en 1999 bajó al 65\%; en 2005 la caída llegó al 54\%. Para una gran mayoría de los jóvenes españoles, según este mismo informe, la religión resulta poco relevante y posee una 
mínima incidencia en sus vidas ocupando uno de los últimos lugares en una escala de valoración de las cosas más importantes para los jóvenes. No obstante, el 53,5\% se declara católico, aunque sólo el 7\% del total de los jóvenes dice cumplir con el ritual de la misa dominical. Un $69 \%$ de los que se consideran católicos o creyentes de otra religión opina que hoy se puede vivir la fe individualmente y que es un asunto privado. Sólo un $2 \%$ se declaran creyentes de una religión distinta de la católica y un $42 \%$ se consideran no religiosos. Esta realidad contrasta con la de los jóvenes de origen magrebí que se declaran mayoritariamente musulmanes creyentes (Harrami, Thielmann). En el caso de España, las jóvenes musulmanas son mayoritariamente de origen marroquí. Nacieron o llegaron a nuestro país debido a procesos de reagrupación familiar y son o van a ser en breve ciudadanas españolas.

\subsection{El peso de lo religioso-identitario en la vida de las mujeres musulmanas a uno y otro lado del Mediterráneo}

De acuerdo con el Estudio sobre la situación de las mujeres a ambos lados del Estrecho de Gibraltar coordinado por Gema González, a partir de la realización de entrevistas a mujeres de uno y de otro lado del Mediterráneo, es decir, marroquíes y españolas, la identidad femenina en la sociedad marroquí está marcada por la religión -y por la tradición-. La religión está presente en todos los aspectos de la vida cotidiana y dicta cómo tiene que comportarse la mujer tanto en la vida pública como privada. La mujer es la principal transmisora de valores religiosos. Entre las entrevistadas se comparte la impresión de que antes las mujeres eran creyentes y religiosas de una forma más tolerante que en la actualidad. Lo vivían de una forma más íntima y privada. La nueva interpretación del islam que ellas consideran que se está imponiendo en Marruecos hace que la religión lo abarque todo. Ello implica que los derechos humanos de las mujeres estén en decadencia (Hirsi Ali 218).

Junto con los cambios sociales y demográficos, en todos los países musulmanes se está produciendo un regreso a una tradición reinventada que hace de la religión y de la identidad musulmanas baluartes que defender. Y he ahí que sean las mujeres las que deban sacrificar su recién estrenada parcela de libertad en nombre del mantenimiento de una identidad entendida como la integridad de la personalidad colectiva. Se persigue principalmente que las mujeres sean madres de musulmanes porque la religión musulmana es la base de la identidad: «La religión es la base de la identidad y la mujer cubierta, su garantía» (Bessis 75).

Sophie Bessis denuncia el retroceso a una tradición que reinventa su conexión con un supuesto islam primigenio y que ignora a los grandes pensadores 
musulmanes que creyeron en la compatibilidad del islam con un pensamiento liberal, abierto, donde el individuo tuviera la posibilidad de pensar por sí mismo. En esta vuelta atrás las mujeres son de nuevo utilizadas para salvaguardar esa supuesta identidad musulmana. Porque, como bien ella explica, los privilegios masculinos en los que se basa el orden establecido están en peligro si la mujer y cada individuo tienen autonomía frente al grupo. Nieves Paradela (24) confirma cómo esta vuelta a un islam tradicional, conservador y anti-moderno, que se inició en los años setenta, no responde a razones esencialistas sino a intereses políticos y estratégicos de los países árabes más ricos como Arabia Saudí, con la complacencia de EE.UU.

En la actualidad, en Marruecos, existe un movimiento feminista dispuesto a seguir luchando por la igualdad desde la defensa de principios que consideran universales (González Santos), después de la consecución de avances legales que han supuesto mejoras concretas para las mujeres, a partir de la reforma de la Mudawana. Sin embargo, la obsesión por la especificidad cultural y por «la identidad musulmana», por el binomio islam-identidad, sigue estando muy presente en la sociedad marroquí y se opone al tríptico modernidad-igualdadsecularización (Amorós, Pérez). Ésta es una característica de las sociedades árabes actuales pero también de las sociedades occidentales postmodernas: se plantean así las contradicciones en las distintas orillas del Mediterráneo al cuestionarse la universalidad de los valores de la modernidad existiendo, a uno y otro lado, el peligro real de buscar refugio en los particularismos culturalistas. La transformación de las relaciones entre los sexos amenaza el orden social, y la cuestión femenina, es decir, el asunto de la libertad y la igualdad de las mujeres, es la cuestión central que preocupa al mundo árabe pues cuestiona la identidad musulmana si las mujeres se niegan a ser sus portadoras. De ahí que si la igualdad y la libertad son considerados valores universales se opte por rechazar la universalidad para refugiarse en la defensa de lo particular, de la propia tradición. Esta postura es fuertemente contestada por intelectuales feministas como Seyla Benhabib (2006a, 33) y Sophie Bessis (23).

\section{LAS JÓVENES DE LA GENERACIÓN PUENTE}

Ser puente, como opción libremente asumida, y formar parte de esa comunicación e intercambio continuos debería poder vivirse por parte de estas mujeres como una condición enriquecedora e integradora. Ser puente es muy distinto a la obligada asimilación o a la también impuesta obligación de refugiarse en las adscripciones culturales heredadas, que impiden, en uno y otro caso, decidir en primera persona pasar libremente al otro lado tantas veces como a una se le antoje. (Jiménez-Delgado 2012, 14)

Feminismo/s 28, diciembre 2016, pp. 147-168 


\subsection{Entre la religiosidad y la laicidad, entre lo heredado y lo elegido}

En la actualidad hay un creciente número de jóvenes que nacieron en España o que llegaron en su niñez por procesos de reagrupación familiar desde Marruecos fundamentalmente y que forman parte de una joven generación de españolas que se sienten musulmanas. Muchas de ellas son estudiantes. Es en este colectivo, en concreto entre quienes cursan estudios postobligatorios, en el que se ha realizado el trabajo de campo.

La tendencia mayoritaria de las jóvenes entrevistadas se sitúa próxima a las y los musulmanes laicizados (Allievi 25). Muestran una actitud crítica tanto con respecto a la sociedad española, de la que sienten que forman parte, como con respecto a la sociedad de origen y a la comunidad marroquí asentada en España. Su actitud es la de puente entre una y otra parte de la sociedad.

De la misma forma que señala el sociólogo franco-persa Farhad Khosrokhavar que ocurre en Francia, las jóvenes estudiantes musulmanas muestran una actitud abierta y receptiva respecto a la sociedad y una actitud más crítica ante la comunidad musulmana -teniendo en cuenta que los musulmanes, como ya se advierte anteriormente, no son una comunidad monolítica y que, por tanto, no existe como tal (Sardar 2015,72)-. Las jóvenes intentan liberarse de los lazos comunitarios para convertirse en ciudadanas españolas aunque no renuncian a su origen familiar. Se encuentran a menudo en una difícil situación que les permite mayor libertad individual pero que genera también incomprensiones de uno y otro lado.

Las jóvenes quieren ser sujetos que deciden qué hacer con lo heredado, entendiendo así la diferencia cultural como el derecho a la reinterpretación y crítica de la propia cultura, entendiendo las culturas como constantes negociaciones y recreaciones de «fronteras imaginarias entre 'nosotros' y el/los 'otro(s)'» (Benhabib 2006a, 33). Reivindican mayoritariamente la igualdad, y la libertad individual y religiosa. Ello no significa que padezcan un proceso de asimilación que las obliga a asumir valores ajenos a su cultura, ni que se vean forzadas a mantener las pertenencias culturales y religiosas heredadas desde una postura multiculturalista (Jiménez-Delgado 2016). Sin embargo, con demasiada frecuencia la sociedad interpreta que están oprimidas y que es necesario ayudar a liberarlas de una cultura rígida y cerrada. Pareciera que esta situación las conduce a un callejón sin salida. Desde el feminismo laico se denuncia esta ambivalencia que genera cierta tolerancia a la desigualdad de género y que conduce a un déficit de libertades individuales por temor a ser criticados como intolerantes e irrespetuosos con la libertad religiosa y la identidad cultural. 
Por otra parte, la filósofa Martha Nussbaum denuncia la intolerancia y la falta de libertad religiosa en Europa que conduce a legislar sobre el uso de los símbolos culturales y religiosos en el espacio público, específicamente sobre la vestimenta femenina, vulnerando así principios democráticos básicos como ha podido comprobarse en el verano de 2016, después del atentado en Niza el 14 de julio de este mismo año (Aguilar, Ramírez 2011, 2016).

Ante esta situación en la que se mezclan la defensa de los principios democráticos con algunas actitudes y decisiones políticas contradictorias con estos mismos principios, es necesario garantizar con claridad los derechos fundamentales y promover el diálogo, el cuestionamiento, la crítica de lo propio y de lo ajeno; ofrecer herramientas a unos y a otros para argumentar, dudar, explicar, preguntar y cuestionar. Porque la aplicación ilimitada del principio de laicidad, sin diálogo y sin posibilidad de analizar la persistencia de formas patriarcales, puede ser tan dogmática como el deseo de que las normas religiosas sean las normas sociales para todos (Frégosi 14). Las jóvenes no son únicamente musulmanas aunque su pertenencia religiosa sea uno de sus componentes identitarios. Sus discursos evidencian también la pluralidad, el dinamismo social y cultural y las diferencias entre una y otra generación.

Me siento española,... marroquí pues la verdad es que menos, más que nada porque no voy, y también porque aquí no tengo mucho contacto con la gente de mi país, pero tampoco es que reniegue de ello. (E19).

Aquí la verdad es que hay muchos árabes...Prefiero que no haya más marroquíes; cada uno tiene una mentalidad, hay gente muy cerrada, gente muy abierta... (E12).

A mí me gustaría ser algo más que una mujer y una madre, que un ama de casa, ser algo más que mi madre. Yo la respeto mucho,... pero quiero ser algo más... Por eso yo todavía sigo soltera y estudio... para no depender de nadie. (E15).

\subsection{Musulmanas a su manera}

Las jóvenes estudiantes entrevistadas se definen como sujetos individuales (Touraine 1997, 2007, 2009), defienden una religiosidad íntima, próxima a la idea del dios personal de la postmodernidad, no expresando necesariamente de forma pública su fe, ya sea por convicción, por prevención o por adaptación social. Aunque más religiosas que las jóvenes de su tiempo, se sienten parte de su generación. Se sienten puente que entabla un diálogo entre el islam heredado y el islam elegido, entre la sociedad de acogida y la sociedad de origen. La construcción del puente, es su propia construcción personal, individual, resultando una tarea difícil, pues implica la voluntad de diálogo continuo con unos y otros, y la curiosidad permanente para imaginar a los otros y conocerlos: 
Así lo expresa una joven que estudia tercer curso del grado de Derecho y que llegó a España con siete años procedente de una pequeña aldea del norte de Marruecos: «A mí me gusta conocer otras religiones, conocer el cristianismo, entender lo que la gente hace...» (E3).

Para la mayoría de las jóvenes, la religión es una parte más de sus vidas, que la mirada social magnifica, de tal forma que puede acabar convenciéndolas de lo decisivo de ese componente identitario, de que es la característica que mejor las define o la única que los otros perciben, y que las diferencia de las otras jóvenes no musulmanas. Como analiza Jaffe-Walter en su estudio sobre la situación de las jóvenes estudiantes musulmanas en Dinamarca, predomina una visión esencialista del islam que elimina la heterogeneidad y la pluralidad. Sin embargo, las vidas de las jóvenes son individuales, plurales, únicas y dinámicas.

Soy musulmana porque he nacido en una familia musulmana, si hubiera nacido en una familia cristiana, sería cristiana (E20).

Yo soy musulmana pero acepto también lo que dicen las otras culturas y me gustaría saber cómo son. A mí me gusta transmitir lo que sé y que la gente me transmita lo que yo no sé... (E12).

La mayoría de las estudiantes entrevistadas se consideran musulmanas, en gran medida creyentes y, más o menos practicantes, siendo una característica o rasgo de su identidad, junto con otros muchos, que las definen. Lo más interesante de sus aportaciones es, la re-significación crítica y personal que hace la mayoría de ellas del islam, que se resume en esta expresión repetida por muchas jóvenes entrevistadas: «Soy musulmana a mi manera». Esta afirmación conecta con una visión global y transnacional del hecho religioso que deja de vivirse como un fenómeno preferentemente cultural e identitario para convertirse en una vivencia propia, personal e íntima, en consonancia con la noción del Dios personal de la postmodernidad, definido por Ulrich Beck como la individualización de la religión, en su ensayo El Dios personal. La individualización de la religión y el 'espiritu' del cosmopolitismo.

Algunas de ellas, se sienten musulmanas antes que magrebíes, marroquíes y/o españolas. La importancia de la adscripción religiosa está relacionada con los procesos de socialización familiar, con la edad que tenían cuando llegaron a España, con la mayor o menor trayectoria en el sistema educativo español y con la percepción del barrio en el que viven, principalmente. Las jóvenes que se incorporaron tardíamente al sistema educativo y que tienen la percepción de vivir en barrios con graves procesos de segregación tienden a resaltar su pertenencia religiosa por encima de otras como la nacionalidad. Así lo afirma una estudiante de 18 años, que vive en España hace tan sólo tres, que sigue escolarizada en el sistema educativo, aunque ha repetido dos cursos de la 
educación secundaria obligatoria, y que afirma no gustarle el barrio donde vive pues, según sus palabras, no parece España ya que lo habitan muchos gitanos, magrebíes y extranjeros, en general.

Para mí es más importante ser musulmana. No me importa la nacionalidad, puedo ser española y qué pasa, es lo mismo... sí que me gusta. Marruecos más, pero vamos, lo que me gusta es ser musulmana (E18).

Pero ¿qué significa para las jóvenes entrevistadas ser musulmanas? ¿Es una adscripción cultural o también religiosa? ¿En qué medida su situación de minoría cultural y/o religiosa dentro de un país democrático mayoritariamente católico -o indiferente cada vez más al hecho religioso- posibilita una elección más libre y una evolución en el significado de esa afirmación que ellas hacen: «Soy musulmana»? En el país de acogida que eligieron sus padres para emigrar, para algunas su lugar de nacimiento y para todas ya su contexto social vital, siendo en su mayoría, o en breve, ciudadanas españolas, la adscripción religiosa no es obligatoria y, por tanto, la afirmación «soy musulmana» es una elección mucho más deliberada.

En el contexto social en el que viven estas jóvenes, hijas de inmigrantes marroquíes, las prácticas y adscripciones religiosas se transforman no solo para ellas sino para toda la comunidad marroquí residente en España. Afirma Jordi Moreras (2006) que hay tres supuestos erróneos respecto a la religiosidad en el contexto migratorio: el del transplante inmutable, el de la homogeneidad interna de los colectivos y el de la centralidad de la cultura y/o religión en la construcción de identidades. Y es que en el contexto migratorio se amplían las referencias existiendo, en el caso de las jóvenes que continúan estudios postobligatorias, plurales influencias socializadoras, $y$, por tanto, mayores posibilidades de tomar decisiones. Ello contribuye a que haya distintos tipos de comportamientos entre estos dos más distantes: el alejamiento de las referencias culturales y religiosas de origen o la reivindicación activa de las mismas, porque la indiferencia es prácticamente inexistente. Entre estas dos posturas se sitúan las jóvenes estudiantes de origen magrebí. Dentro de la ampliación de referencias culturales, religiosas y de otro tipo, la escolarización y la continuidad en los estudios postobligatorios, condiciona las distintas elecciones ya que resulta ser una influencia secularizadora importante.

Y es en este punto donde se rescata esta expresión frecuente en el discurso de las jóvenes universitarias entrevistadas, hijas de familias marroquíes: «Soy musulmana a mi manera». La religión pasa a ser religiosidad recreada y vivida en gran medida en el ámbito de lo privado, convirtiéndose la creencia religiosa en una opción personal más allá de ser una pertenencia familiar y cultural 
heredada. La práctica religiosa, en su dimensión comunitaria, es también respetada por las dos estudiantes que se declaran no creyentes.

Aunque no soy creyente, yo las fiestas religiosas las practico pero no porque diga 'ay, cómo me gusta mi religión' pues para mí es como aquí se celebra la navidad (E11).

Las jóvenes se apropian de forma reflexiva y crítica de la tradición, característica de la modernidad, para ejercer de sujetos y decidir así qué hacer con lo heredado, de acuerdo con Seyla Benhabib (2006a). Para estas jóvenes el cuestionamiento de las pertenencias heredadas, entre ellas la religión, cobra una importancia mayor que para otras jóvenes españolas debido a dos cuestiones principalmente: un contexto en el que se sienten en minoría y una mirada social que les confirma esta situación. Por otra parte, hay cierta presión, del grupo familiar y sobre todo de la comunidad marroquí que vive en los mismos barrios que estas jóvenes, para que asuman y mantengan las tradiciones y costumbres propias de la religión musulmana -aunque el contexto lo dificulte, o precisamente por ello-. Estas presiones son mucho mayores para las mujeres, con un mayor control social, al ser consideradas menores de edad respecto a los varones, y al peso que recae sobre ellas para mantener la identidad musulmana que se traduce en el deber de llegar a ser madres de musulmanes (Bessis). Porque como afirma Fatima Mernissi, son las mujeres las encargadas de la transmisión cultural y, por tanto, son ellas las que pueden introducir cambios en esta transmisión y consecuentemente en la mentalidad de las nuevas generaciones. Así hablan del control y la presión social de la comunidad marroquí dos jóvenes universitarias que llegaron con diez años a vivir a España y que estudian 3. ${ }^{\circ}$ de Traducción e Interpretación y 2. ${ }^{\circ}$ de Filología Árabe:

Cuando vives en un barrio donde hay más vecinos que son de tu país,... hay más control social, hay muchísimo más control social y, claro, pues sí, te condiciona bastante (E19).

El problema no son mis padres...Yo, por ejemplo, donde vivo la mentalidad es super cerrada... Viven en España pero no saben nada de aquí...y cotillean e intentan controlar tu vida... (E15).

\subsection{La religiosidad des-institucionalizada}

Para Moreras (2006), el aumento de las mezquitas en España coincide temporalmente con los procesos de reagrupación familiar y con nuevas demandas relacionadas con la presencia de la segunda generación representada por los hijos y las hijas de las familias inmigrantes. Sin embargo, en el caso de las jóvenes entrevistadas, las mezquitas tienen escasa influencia en su religiosidad. Por 
un lado, existe una menor vinculación y obligación por parte de las mujeres, que tiene como consecuencia que la asistencia a las mismas sea mayoritariamente masculina -existe un hadiz según el cual el Profeta habría dicho: «No impidáis que vuestras mujeres vayan a la mezquita, pero es mejor que recen en casa» (Bramon 114-115)-. Por otro, las jóvenes cuestionan la autoridad y la formación de los imanes, pues los consideran, en muchos casos, mal preparados y en algunos, más radicales o más estrictos con las prácticas religiosas y las costumbres que en el propio Marruecos.

En la narrativa siguiente, de una estudiante de $1 .^{\circ}$ de bachillerato que llegó a España con diez años, se defiende una religiosidad no vinculada a la asistencia a la mezquita ni al uso del velo, sino a una vivencia interior:

Yo soy musulmana y lo defiendo pero ya lo de ir a la mezquita... Soy musulmana de creencia, si tú crees que eres musulmana eres musulmana dentro de ti. No estás haciendo ningún pecado estás intentando sacar tu vida y ser algo bien pero no es necesario llevar pañuelo, ni ir a la mezquita todos los días ni nada. Porque hay gente que va a la mezquita pero de musulmanes no tienen nada... Los imanes preparación no tienen ninguna... Mi religiosidad es mía y ya está, yo no hago nada malo. Acepto lo que hay y ya está, por ejemplo, no bebo, no fumo, no como cerdo... porque yo lo quiero respetar (E12).

Otra estudiante que se declara no muy religiosa confiesa no haber entrado nunca a una mezquita y critica que los imanes se otorguen así mismos autoridad para opinar fuera de ellas sobre asuntos relacionados con la libertad de las mujeres como usar velo o no llevarlo.

Parece mentira pero jamás en la vida he entrado a una mezquita; he estudiado cómo es una mezquita pero nunca he ido, ni en Marruecos ni aquí. Las mezquitas sé que están repletas de hombres, mujeres hay muy pocas, y poco más, no tengo un gran conocimiento del tema, la verdad A veces los imanes hablan en nombre de las mujeres como con lo del velo (...) se supone que esa persona [una mujer] tiene cabeza suficiente como para hablar ella misma... (E19).

Hay consenso entre las jóvenes entrevistadas respecto a la escasa formación de los imanes que desacreditan sus discursos, tanto dentro como fuera de las mezquitas. Una estudiante de tercer curso de Ciencias Empresariales dice:

No es que sean conservadores, yo creo que ni siquiera deberían ejercer de imanes, porque no tienen, creo yo, el conocimiento suficiente para hacerlo... Ellos no representan ni al 0,0001 por cien de las musulmanas. Hablan de acuerdo con lo que ellos piensan, no con lo que hay ni con lo que la gente quiere o cree. Dicen lo que ellos piensan y claro, como se suponen que son los portavoces... (E14).

Esta misma estudiante insiste en el carácter personal tanto del sentimiento religioso como de las opiniones o forma de pensar suya como musulmana. 
Hay una defensa de los derechos individuales y una crítica al comunitarismo en la medida en que la estudiante rechaza que los imanes, desde las mezquitas, hablen en su nombre, como musulmana, como si formaran un colectivo homogéneo.

Es un error por parte del gobierno que escuche a los imanes, es un error porque cada cual es libre. Vale que seas el imán, pero vale, a lo mejor yo voy a rezar a tu mezquita pero es que ni eres mi padre, ni eres mi madre, ni eres nada mío, tú tienes tus ideales, yo tengo los míos. Que hay un conflicto vale, a lo mejor estamos de acuerdo en eso, pero el resto que puedas decir a partir de ahí, eso ya es tu forma de pensar, tu forma de ver las cosas, no tiene nada que ver con el resto de personas (E19).

Las jóvenes estudiantes de origen marroquí, sujetos de la investigación, valoran especialmente del islam su dimensión espiritual. Hacen de este modo una reinterpretación de la religión heredada realizando el tránsito de una religión hecha de obligaciones y prohibiciones, especialmente para las mujeres, a una religión de creencias y de espiritualidad (Touraine 2007, Beck). Una estudiante de tercer curso de Ciencias Químicas, que llegó con siete años, afirma: «La religión yo la vivo en mi corazón, no tengo porqué ir a una mezquita...» (E20).

Una característica significativa de las jóvenes estudiantes de la generación puente, es que no asumen, en su mayoría, el islam de manera acrítica, como una imposición del grupo cultural de origen o de la familia. Ser musulmanas forma parte de su identidad pero desde un cierto distanciamiento de las prácticas más tradicionales que consideran patriarcales. Hay, así mismo, una desinstitucionalización de la fe, como ocurre en general también con otras creencias religiosas en España (Tamayo-Acosta).

En definitiva, hay un interés manifiesto en marcar la diferencia entre la religiosidad que ellas viven y la imagen que se transmite en los medios de comunicación sobre el islam, entre sus formas personales de sentirse religiosas y la influencia de los imanes, a quienes les otorgan muy poca credibilidad por su escasa formación, además de que su estatuto eclesiástico se defina vagamente. Algunas de las jóvenes, que se consideran poco religiosas, aunque sí se sienten musulmanas, valoran sobre todo el mensaje de paz, de hospitalidad y de solidaridad con los más necesitados del islam.

La religiosidad es considerada una vivencia personal y a lo sumo familiar. Suelen respetar y participar de las prácticas musulmanas como el ramadán, dotando de sentido el ayuno por cuanto ayuda a experimentar el significado del hambre y a ponerse en el lugar de quienes la padecen. Además de valorar el ritual y la solidaridad familiar que sienten con sus padres, hermanas y hermanos cuando se reúnen a cenar después de pasar todo el día en ayunas: «Yo 
sé que a las ocho voy a comer pero esa gente no va a comer...Qué sensación más dura la del hambre... Más o menos te conciencias» (E20).

\subsection{El proceso de individualización personal y religiosa}

Las jóvenes estudiantes se perciben a sí mismas mucho más críticas con el islam que sus compañeros varones marroquíes de la misma edad, aunque ello no se traduce en el rechazo a su condición de musulmanas. Las estudiantes expresan rechazo a las instituciones religiosas porque ven en ellas una perpetuación de las tradiciones patriarcales y, por tanto, una discriminación hacia las mujeres. Es esta una cuestión importante que tiene consecuencias en la transmisión religiosa y cultural, y revela nítidamente que ésta es dinámica y está abierta a otras influencias. Así las mujeres asumen su condición de sujetos que recrean lo cultural y religioso heredado, de forma que no rechazan la cultura de origen, en la mayoría de los casos, sino que reinterpretan y reconstruyen la herencia familiar. En este sentido, las diferencias con los varones son evidentes:

Los chicos marroquíes no toleran que seas inteligente, porque si eres inteligente puedes pensar. No lo tolera aunque haya estudiado, aunque sea ministro... (E11).

Los chicos marroquíes es que tienen una mentalidad totalmente distinta a las chicas marroquíes... porque ellos quieren que seas tú la que mantenga las costumbres religiosas y ellos hacen lo que quieren... Hay bastante falsedad (E19).

Las jóvenes conciben mayoritariamente la religión como una práctica individual ligada a la creencia y al establecimiento de un vínculo directo con Dios, otorgando menos importancia y, por tanto, relativizando el cumplimiento de ciertas obligaciones religiosas impuestas por los imanes, por la familia y por la comunidad marroquí residente en España. En todo caso, la pluralidad de matices y de vivencias de lo religioso pone en evidencia la misma diversidad dentro de esta generación de mujeres jóvenes musulmanas en España. La narrativa siguiente recoge una opinión mayoritaria sobre la vivencia de lo religioso y los símbolos como el velo o hiyab; debe der libre, cada cual tiene que tener derecho a decidir individualmente cómo ser religiosa o no serlo:

Debería ser libre, dejar a cada persona que decidiera como quisiera... porque si no lo haces con tu voluntad... o sea no vale nada la religión. Es algo personal. Yo lo veo como una cosa muy personal: entre Dios y yo. Y ya está. Y se acaba. Y no mezclo las cosas. (E2)

Esta es una declaración explícita de vivencia personal de lo religioso, es decir, de religiosidad personal y cosmopolita. Hay reconocimiento y aceptación de otras religiones y voluntad de vivir de forma íntima y privada el hecho religioso. 
Algunas de las jóvenes muestran incluso su escepticismo respecto a la religión musulmana o a cualquier otro credo religioso, como esta estudiante de segundo curso del Grado de Maestra de Educación Primaria, nacida en España:

Si tengo hijos...la educación sobre la religión... yo creo que desde ninguna, y la cultura desde las dos, como yo soy... Yo es que lo de la mezquita sinceramente no me lo creo. No entiendo como una persona que no tiene estudios de nada, que solo sabe leer y escribir esté dando clase de religión a unos niños (E11).

Por otra parte, el análisis de la espiritualidad y religiosidad de las jóvenes musulmanas entrevistadas muestra las contradicciones de la misma sociedad. En este sentido, a pesar de la retórica oficial y políticamente correcta que dice valorar y respetar el pluralismo cultural y religioso, lo cierto es que en la mayoría de las escuelas es casi únicamente una religión -la católica- la que es ofertada a los alumnos (Moreras, 2015). Existe una contradicción cuando se defiende el pluralismo y sólo se facilita la enseñanza de una religión (JiménezDelgado, 2016). En este sentido, las jóvenes parecen tener una visión más tolerante y cosmopolita cuando reclaman y proponen una formación plural en la que todas las religiones tengan cabida desde una perspectiva histórica y sociológica, sin adoctrinamiento. No consideran la religión mayoritaria, algo extraño o amenazador sino algo que les enriquece y que, por tanto, valoran positivamente, como la siguiente estudiante de tercer curso de Traducción e Interpretación:

En las escuelas yo creo que tienen... tienen que hablar de todas las religiones, porque hay que saber un poco de todo. Por ejemplo, aquí en España, los españoles no saben nada de mi cultura de origen. Yo sí que sé algo de la cultura de aquí y de la religión (E2).

La cuestión es cómo hablar y tratar en la escuela el asunto de la libertad individual, de la igualdad de género y de la libertad religiosa sin reforzar estereotipos y sin menospreciar las identidades de cada una de las jóvenes. Hay una gran dificultad para tratar en el espacio público y, en las instituciones educativas particularmente, estos temas y, al mismo tiempo, hacer crítica de la deriva tribal o comunitarista identitaria. Como sugiere Bowen (63), es necesario enseñar la realidad social de la religión en las escuelas públicas y para ello resulta urgente formar al profesorado.

En la vivencia religiosa de las jóvenes hay un proceso de integración de las tradiciones y perspectivas de los otros que les permite aprender más sobre sí mismas y sobre lo que les rodea. Y esto es lo que llama Beck, cosmopolitismo religioso, que está próximo a la percepción de otras creencias como 
aportaciones que enriquecen la propia. Una joven quiso cursar la asignatura de religión católica:

Yo, en el instituto, me apunté a religión y el director me dijo: «Somaya, ¿tú religión? Porque claro era católica....Me miró con una cara...Yo soy musulmana pero es que yo vivo en una sociedad que dicen que son cristianos...Pues yo quería saber qué es el cristianismo... (E3).

Es importante, por tanto, señalar el papel activo y fundamental que tienen estas jóvenes en una sociedad más pluralista por cuanto en ellas se hace realidad la sustitución de una mirada nacional homogeneizadora, ligada a un único universo religioso, por una mirada más cosmopolita.

\section{CONCLUSIONES Y ALGUNAS PROPUESTAS}

Las jóvenes forman parte de la pluralidad y el cosmopolitismo religioso que no considera lo ajeno a las propias pertenencias, ya sea la religión o la cultura, algo amenazador sino algo que las enriquece y que les permite construir con mayor libertad su yo. Sus identidades religiosas superan el ámbito nacional para identificarse con algo que amplía las fronteras nacionales: lo musulmán. ¿Es esta situación percibida con recelo en cuanto que Europa y sus estados nacionales no acaban de asumir la pluralidad religiosa y el lugar que debe ocupar lo musulmán como religión también europea?

Todavía en España profesar la religión musulmana y tener pasaporte español es una conjunción insólita. Es un reto saber cómo afrontar, desde el respeto democrático, que un grupo importante de ciudadanos que son europeos y españoles, reivindiquen su derecho a profesar la religión musulmana en las mismas condiciones que otras religiones, sin sentirse discriminados ni rechazados. En la pretensión de las jóvenes de la generación puente de ser reconocidas como ciudadanas europeas musulmanas, la sociedad en general suele ver la posibilidad de legitimar una forma de vida alternativa a la mayoritaria, que cuestiona los principios dominantes de la sociedad española. Ser religiosa o religioso debería ser compatible con la modernidad y con el laicismo. Sin embargo, en la actualidad parece que puede resultar conflictivo. Por una parte, hay una idea equivocada de la laicidad cuando se pretende imponer una «no creencia» o «no fe» como más respetable que la religiosidad (Gamper, Nussbaum). Por otra, queda lejos de la realidad la separación entre las instituciones del Estado y las religiones y el igual trato a todas ellas, que debe también definir la laicidad en una sociedad. En España, la Constitución Española, en su artículo 16.3, reconoce un trato preferente a la iglesia católica. Es imprescindible equilibrar 
esta situación para garantizar los mismos derechos y deberes para todos los ciudadanos y ciudadanas de una sociedad plural.

La religión musulmana en Europa se distancia de la cultura de origen y se acomoda a las nuevas circunstancias sociales, culturales, económicas y políticas. Según Roy $(2005,2010)$ la condición para el islam europeo es más bien la desculturalización del islam. Así nacen formas individualizadas de religiosidad musulmana, como lo corroboran las narrativas de las jóvenes entrevistadas como la siguiente: «Para mí, la religión es cosa mía y de Dios» (E3).

La religión musulmana se desliga de sus normas y obligaciones territoriales y se convierte, en gran medida, en una religiosidad basada en la decisión de los individuos. La nueva conciencia musulmana que expresan, por ejemplo, las jóvenes que se ponen el velo o el fundamentalismo religioso de los musulmanes que viven en Occidente no son fruto de la importación de una cultura musulmana original y territorial (Roy 2005). Sin embargo, las jóvenes se adscriben de algún modo al concepto de «cultura musulmana» como transformación de las normas religiosas en habitus, es decir, en comportamientos interiorizados y estables que no dependen de la fe ni de la creencia y que son normas culturales referidas a la familia, las fiestas o la alimentación (Roy 2010).

Entre las musulmanas entrevistadas también se da un alejamiento de los lugares sagrados y de las autoridades y organizaciones religiosas, por lo que tienden a crear una nueva espiritualidad, caracterizada por la búsqueda, la elección y la combinación -lo que pone también al islam bajo el primado de la fe individual-. La individualización de la praxis religiosa es, en consecuencia, un elemento dominante de la religiosidad musulmana en Europa, que, desterritorializada y mediante la construcción de una comunidad o ummah imaginaria, posibilita una socialización por encima de las fronteras.

Las jóvenes estudiantes hacen una re-significación crítica y personal del islam que se resume en esta expresión repetida por muchas de ellas: «soy musulmana a mi manera». Esta percepción de su propia religiosidad está condicionada por el género y conecta con una visión transnacional del hecho religioso que deja de vivirse como un fenómeno preferentemente cultural e identitario para convertirse en una vivencia íntima y espiritual, en consonancia con la noción de Dios personal de la postmodernidad, definido como la individualización de la religión. Consecuentemente, las jóvenes no reclaman clases de religión islámica en las instituciones educativas, ni siquiera mezquitas en sus barrios, aunque sí el uso libremente elegido de símbolos culturales y/o religiosos como el hiyab y un mayor conocimiento por parte de la sociedad española, especialmente por parte del profesorado y del alumnado, del islam y de los contextos sociales y políticos de los que proceden sus familias. Hay 
un acomodo a un mundo secularizado donde se propicia la vivencia íntima y privada. Sin embargo, todavía la sociedad española, como otras sociedades europeas, debe garantizar el respeto a la pluralidad religiosa -concretando su presencia o ausencia-, en igualdad de condiciones en el espacio público y, más concretamente en la institución educativa.

Las jóvenes están redefiniendo el islam, haciendo evidente la existencia de pluralidad dentro de la misma juventud y entre ésta y sus familias. Por otra parte, sus discursos ponen de relieve la importancia decisiva de su condición de estudiantes de educación postobligatoria así como la necesidad de combatir los procesos de segregación urbana y escolar (Jiménez-Delgado, Jareño y El Habib, 2016). Reclaman liberarse del control social, tener oportunidades para formarse, poder construir con mayor libertad su propia identidad (Abbas 2015) y participar en la sociedad como ciudadanas de pleno derecho.

Por último, promover políticas activas contra la radicalización (Fregosi 17) -una de las mayores preocupaciones sociales- implicaría escuchar a las jóvenes y sus principales demandas. Urge conocer y reconocer la pluralidad dentro del mismo islam por parte de la sociedad española y europea. Además de que forme parte de una pedagogía social, el conocimiento del pluralismo religioso y el respeto a la libertad religiosa y a las libertades individuales en general, debe ser un objetivo del currículo en la educación secundaria.

Resulta esencial, como afirman Martha Nussbaum y Amos Oz, hacer hincapié en la necesidad de imaginarnos unos a otros y de escuchar al otro, incluso cuando tenemos la convicción de tener razón y de que es el otro el que está equivocado. Hacernos la sencilla pregunta de qué pasaría si yo fuera ella, si yo fuera él. Escuchar y conocer al otro debería formar parte de un proyecto educativo democrático y, por tanto, participativo y pluralista, crítico, abierto a la discusión y el debate, en la línea que propone Seyla Benhabib (2006a, 2006b). Esta es la esencia misma de una sociedad más democrática que promueve, desde sus instituciones y desde la sociedad civil, la participación de cada ciudadana y de cada ciudadano, con sus particulares y diversos argumentos, con el fin de conseguir acuerdos de mínimos que nos permitan reconocernos y convivir con los demás en pie de igualdad.

\section{REFERENCIAS BIBLIOGRÁFICAS}

Aguilar, Pilar. «Burkinimanía, política y feminismo». Tribuna Feminista: Agosto de 2016.

Allievi, Stephano. «Los islams europeos: una realidad interna con vinculaciones externas». Vanguardia Dossier 56 (2015): 21-27. 
Amorós, Celia. Vetas de Ilustración: reflexiones sobre feminismo e Islam. Madrid: Cátedra. 2009.

Beck, Ulrich. El Dios personal: la individualización de la religión y el «espíritu» del cosmopolitismo. Barcelona: Editorial Paidós, 2009.

Benhabib, Seyla. Las reivindicaciones de la cultura. Igualdad y diversidad en la era global. Buenos Aires: Katz -editores, 2006a.

Benhabib, Seyla. El Ser y el Otro en la ética contemporánea. Feminismo, comunitarismo y posmodernismo. Barcelona: Gedisa, 2006b.

Benhabib, Seyla. Los derechos de los otros. Extranjeros, residentes y ciudadanos. Barcelona: Gedisa, 2005.

Bessis, Sohie. Los árabes, las mujeres, la libertad. Madrid: Alianza Editorial, 2008.

Bowen, John R. «Francia después de 'Charlie Hebdo'». Vanguardia Dossier 56, (2015): 56-63.

Bramon, Dolors. Ser mujer y musulmana. Barcelona: Editorial Bellaterra, 2009.

Frégosi, Frank. «El islam en Europa... bajo el prisma de las polémicas y los miedos sociales». Vanguardia Dossier 56, (2015): 6-17.

Gamper, Daniel. «¿Por qué la religión hoy?» La maleta de Portbou 16. (2016): 36-41.

Glaser, Barney.G., \& Strauss, Anselm.L., The Discovery of Grounded Theory: Strategies for Qualitative Research. New York: Aldine Publishing Company, 1967.

González Ferrera, Gema. (Coord.). Estudio sobre la situación de las mujeres a ambos lados del Estrecho de Gibraltar. Cádiz: Instituto Andaluz de la Mujer. 2006.

González Santos, M. ${ }^{a}$ Teresa. «Los movimientos feministas y femeninos en Marruecos y su transposición a la dinámica marroquí en Francia». Feminismo/s 26 (2015):197-220.

Goodman, Leo A. «Snowball Sampling». The Annals of Mathematical Statistics 32 (1961): 148-170.

Harrami, Noureddine «Conductas religiosas de la juventud musulmana». Afkar/ Ideas 3 (2004): 33-36.

Hirsi Ali, Ayaan. Reformemos el islam. Barcelona: Galaxia Gutemberg, 2015.

Jiménez-Delgado, María. «Discursos interculturales y prácticas asimilacionistas: algunas contradicciones en el sistema educativo español». Convergencia Revista de Ciencias Sociales 71 (2016): 41-62.

Jiménez-Delgado, María., Jareño-Ruiz, Diana y El-Habib, Brahim. «La inclusión educativa y social de las jóvenes de origen inmigrado a través de la educación postobligatoria». Prisma social. Revista de ciencias sociales 16, (2016): 411-449.

Khosrokhavar, Farhad. «Las nuevas clases medias musulmanas y su alienación». Vanguardia Dossier 56 (2015): 64-69.

Mernissi, Fatima. El poder olvidado. Las mujeres ante un Islam en cambio. Barcelona: Editorial Icaria, 1995. 
Moreras, Jordi. «Creencias más allá de las fronteras: las expresiones religiosas en contexto migratorio». Puntos de vista: Cuadernos del Observatorio de las Migraciones y la Convivencia Intercultural de la Ciudad de Madrid (oMci) 7 (2006): 21-47.

Moreras, Jordi. «Al Ándalus queda muy lejos». Vanguardia Dossier 56. (2015): 100-103.

Nusbaumm, Martha C. La nueva intolerancia religiosa. Barcelona: Editorial Paidós, 2013.

Oz, Amos. Contra el fanatismo. Madrid: Siruela, 2003.

Paradela, Nieves. «El feminismo árabe y su lucha por los derechos de la mujer». Feminismo/s 26 (2015): 17-32.

Pérez Mateo, Mariví. «Murchidat: renacimiento islámico femenino como control estatal del discurso religioso en Marruecos». Feminismo/s 26 (2015): 175-196.

Ramírez, Angeles. La trampa del velo. El debate sobre el uso del pañuelo musulmán. Madrid: Catarata, 2011.

Ramírez, Angeles «El burkini: totalitarismo, patriarcado y xenophobia en la Europa de las libertades» El Diario, 24 agosto 2016.

Reva Jaffe-Walter. «Who would they talk about if we weren't here? Muslim Youth, Libera -schooling, and the Politics of Concern». Harvard Educational Review 83.4 (2013): 613-635.

Roy, Olivier. «Islam en Occidente: ¿la occidentalización del Islam?» Conferencia pronunciada en el Foro de la FRIDE sobre Oriente Medio y Norte de África (2005). 30 de junio de 2016.

Roy, Olivier. La santa ignorancia. El tiempo de la religión sin cultura. Barcelona: Península, 2010.

Sánchez-Capdequí, Celso. «Las formas de la religión en la sociedad moderna». Papers 54 (1998): 169-185.

Sardar, Ziauddin. «Reino Unido. Una identidad forjada en la confianza y en la simbiosis». Vanguardia Dossier 56 (2015): 70-75.

Tamayo Acosta, Juan J. «Los jóvenes y el diálogo interreligioso». Revista de estudios de juventud 80. (2008): 47-59.

Thielmann, Jörn. «'Cool' y religiosos: los jóvenes musulmanes europeos y sus culturas» Vanguardia Dossier 56. (2015): 39-42.

Touraine, Alain. ¿Podremos vivir juntos?: iguales y diferentes. Madrid: PPC, 1997.

Touraine, Alain. El mundo de las mujeres. Barcelona: Paidós, 2007.

Touraine, Alain. La mirada social. Un marco de pensamiento distinto para el siglo XXI. Barcelona: Paidós, 2009.

Valles, Miguel S., Técnicas cualitativas de investigación social. Madrid: Síntesis, 1997.

Valls Iparraguirre, Maite. «Las creencias religiosas de los jóvenes» en GonzálezAnleo, Juan de Dios y González-Blasco, Pedro (eds.). Jóvenes españoles 2010. Madrid: Fundación SM, 2011. 